
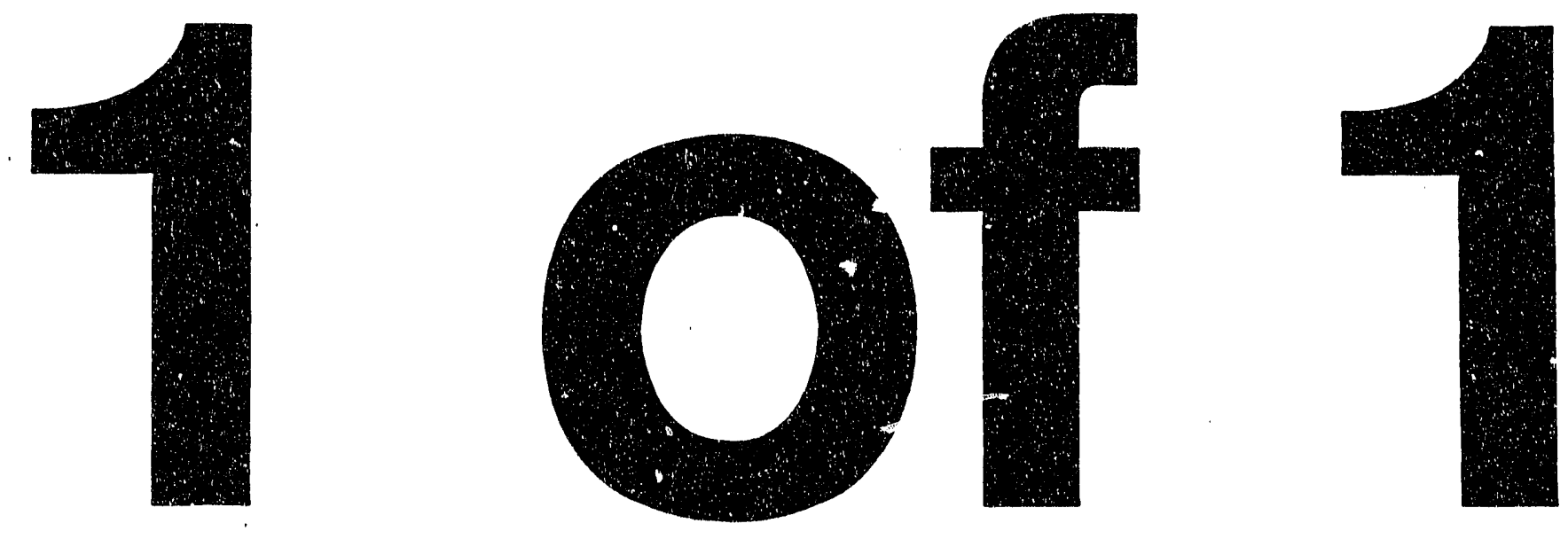


\title{
Conf-950629--6
}

\section{EFFECT OF CYCLIC LOADING ON THE CREEP PERFORMANCE OF SILICON NITRIDE}

\author{
Andrew A. Wereszczak, Mattison K. Ferber, and Timothy P. Kirkland \\ High Temperature Materials Laboratory \\ Oak Ridge National Laboratory \\ Oak Ridge, Tennessee \\ Chih-Kuang J. Lin \\ Department of Mechanical Engineering \\ National Central University \\ Chung-Li \\ Taiwan
}

\begin{abstract}
Tension-tension cyclic fatigue tests (triangular waveform, $\sigma_{\max }=100 \mathrm{MPa}, \quad R=0.1$ ) were conducted on hot isostatically pressed (HIPed) silicon nitride at frequencies spanning several orders of magnitude $\left(5.6 \times 10^{-6}\right.$ to $0.1 \mathrm{~Hz}$ or $10^{-3} \mathrm{MPa} / \mathrm{s}$ to $18 \mathrm{MPa} / \mathrm{s}$ ) at $1370^{\circ} \mathrm{C}$ in air. The amount of cyclic creep surain was found to be a function of the frequency or stressing rate with greater strains to failure observed as the frequency or stressing rate decreased. The total strain was viewed as the sum of elastic, anelastic (or transient recoverable), and plastic (viscous or non-recoverable) strain contributions, after the empirical $\mathrm{Pao}$ and Marin model. The plastic strain was found to be the dominant component of the total creep and was unsatisfactorily represented by the Pao and Marin model. To circumvent this, a time exponent was introduced in the plastic strain term in the Pao and Marin model. This modification resulted in good correlation between model and experiment at the slower frequencies examined but over-predicted the cyclic creep strain at the faster frequencies. The utility of using the modified Pao and Marin model to predict cyclic creep response from static creep and strain relaxation tests is described.
\end{abstract}

\section{INTRODUCTION}

Many structural components are subjected to cyclic loading at elevated temperatures. For example, a cyclic change in angular velocity of a spinning gas turbine rotor will change the centrifugal force and corresponding stress in a cyclic fashion of any given point within the rotor's material. For lifetime prediction, it is important that the component designer understands the candidate material's response to such a cyclic stressing condition. However, high temperature, tensile, cyclic fatigue data for structural materials such as HIPed silicon nitride is lacking in the literature. The cyclic creep response and affiliated damage mechanisms of some silicon nitride materials have been methodically examined in tension. However, these studies were conducted on either immature material by today's standards (Liu and Brinkman, 1987) or on material that is no longer commercially available (Lin, et. al., 1994).

The motive of the present study was to examine the utility of extending values and parameters generated from static creep tests to predict cyclic loading response. Numerous tensilestatic creep tests have been reported in the literature the last few years on various silicon nitrides (Ferber and Jenkins. 1992, Ding, et. al, 1994, and Menon, et, al., 1994), therefore an extensive database is available for static creep tests. The ultimate goal is to he able to take advantage of the more extensive static creep databases to predict cyclic creep response via an appropriate model.

The present study: (1) extracts data from previously generated static creep tests conducted on a HIPed silicon nitride material. (2) describes strain relaxation tests that were conducted as an analytical supplement, (3) describes how an existing empirical model, that describes static creep, was modified to accommodate dynamic or cyclic loading, (4) predicts the cyclic creep response using information from the static and strain relaxation test sources, and then (5) compares it with experimentally generated cyclic creep responses. Along the way, important insights were made with regards to the role of the viscoelastic or anelastic secondary phase on the cyclic creep performance and are presented.
The submitted manuscript has been withored by contractor of the U.S. Gomernments under contract Pto. DEACO5-840A2 1400. ACcordingty, the U.S. Government reteine a nonoxchuive. roverity-free thenes to publiah or reproduce the putlahed form of ith contribution, if slow othere to so so, tor U.S. Lovernment purposes." 


\section{DISCLAIMER}

This report was prepared as an account of work sponsored by an agency of the United States Government. Neither the United States Government nor any agency thereof, nor any of their employees; makes any warranty, express or implied, or assumes any legal liability or responsibility for the accuracy, completeness, or usefulness of any information, apparatus, product, or process disclosed, or represents that its use would not infringe privately owned rights. Reference herein to any specific commercial product, process, or service by trade name, trademark, manufacturer, or otherwise does not necessarily constitute or imply its endorsement, recommendation, or favoring by the United States Government or any agency thereof. The views and opinions of authors expressed herein do not necessarily state or reflect those of the United States Government or any agency thereof. 


\section{MATERIAL DESCRIPTION AND EXPERIMENTAL PROCEDURE}

PYG silicon nitride ${ }^{1}$ was the material examined in this study. The material contained $6 \mathrm{wt} \%$ yttrium oxide as a densification aid. Specimens were cold isostatically pressed. glass-encapsulated, and then HlPed. The as-received microstructure consisted of acicular-shaped grains (typically $\approx$ $0.7-1.5 \mu \mathrm{m} \times 4-10 \mu \mathrm{m})$ mixed with equiaxed grains $\Leftrightarrow 1 \mu \mathrm{m}$ diameter). These silicon nitride grains were separated by thin layers $(\approx 1-3 \mathrm{~nm})$ of an amorphous yttrium-silicon oxynitride. However, most of the secondary phase was located at multigrain junctions. X-ray diffraction was conducted on the asreceived material of one of the test specimens and $\beta_{-S_{3} \mathrm{~S}_{4}}$ was identified along with a trace of $\alpha \cdot \mathrm{Y}_{2} \mathrm{Si}_{2} \mathrm{O}_{7}$ (JC.PDS\#21-1457). The $\alpha-\mathrm{Y}_{2} \mathrm{Si}_{2} \mathrm{O}_{7}$ phase was mostly at the multi-grain junctions.

Button-head tensile specimens $(6.35 \mathrm{~mm}$ gage diameter and $35 \mathrm{~mm}$ gage length) were used. Tension-tension cyclic tests were conducted at $1370^{\circ} \mathrm{C}$ in ambient air $(40-60 \% \mathrm{RH}$ and $25^{\circ} \mathrm{C}$ ). A triangular waveform was used in all tests with $\sigma_{\min } / \sigma_{\max }=R=0.1$ and $\sigma_{\max }=100 \mathrm{MPa}$. Specimens were loaded at one of several frequencies (or stressing rates) that varied over several orders of magnitude. T'est frequencies were $0.1,0.0056,0.00056,0.000056$, and $0.0000056 \mathrm{~Hz}$, which corresponded to stressing rates of $18,1,0.1,0.01$, and $0.001 \mathrm{MPa} / \mathrm{s}$, respectively. Due to a limitation in the number of specimens, only one specimen per frequency was tested. As a supplement to the cyclic testing, strain (or creep) relaxation tests were conducted at $1370^{\circ} \mathrm{C}$. This involved removing a $100 \mathrm{MPa}$ stress from a tensile specimen in a matter of a few seconds and monitoring the strain or creep recovery as a function of time. The motive behind the strain relaxation tests was to examine the relaxation behavior of this material at $1370^{\circ} \mathrm{C}$ and to correlate it with the cyclic hehavior of the material.

All tests were conducted on electro-mechanical tensile test machines in electronic closed-loop load control. ${ }^{2}$ Specimens were heated using a compact two-zone, resistance-heated (MoSi 2 elements) furnace having six elements per zone. Specimen grips were positioned outside the furnace hot zone. The grips and couplers were tensile-load-activated and were designed to minimize specimen bending. Specimen elongation was measured over a $25 \mathrm{~mm}$ gage length using a high temperature, contact extensometer that employed a capacitance sensor. Extensometer accuracy and stability of approximately $0.5 \mu \mathrm{m}$ over the $25 \mathrm{~mm}$ gage length was achieved. Personal computers were used to acquire load, load error, specimen elongation, and furnace temperature data as a function of time.

\section{RESULTS AND DISCUSSION}

\section{Medification of the Pae and Marin Model}

The empirical Pao and Marin model (Pao \& Marin, 1953) was chosen because it was already in a form that could readily

${ }^{1}$ GTE Laboratories, Inc., Waltham, MA (1989-90 vintage).

${ }^{2}$ Model 1380, Instron Corp., Canton, MA. accommodate variable stressing conditions in its prediction of creep strain. In the Pao and Marin (PM) model, the total isothermal strain $\left(\varepsilon_{t^{\prime}}\right)$ at any time is composed of three independent terms; the elastic strain $\left(\varepsilon_{\mathrm{e}}\right)$, the anelastic or transient or recoverable non-clastic strain $\left(\varepsilon_{\mathrm{q}}\right)$, and the plastic or non-recoverable strain $\left(\varepsilon_{\mathrm{p}}\right)$. This is represented by:

where,

$$
\varepsilon_{\mathrm{t}^{\prime}}=\varepsilon_{\mathrm{e}}+\varepsilon_{\mathrm{a}}+\varepsilon_{\mathrm{p}}
$$

(2)

$$
\begin{gathered}
\varepsilon_{\mathrm{e}}=\frac{\sigma}{\mathrm{E}} \\
\dot{\varepsilon_{\mathrm{a}}}=\frac{\mathrm{d}}{\mathrm{dt}}\left(\varepsilon_{\mathrm{a}}\right)=\alpha\left(\mathrm{C}_{1} \sigma^{\prime \prime}-\varepsilon_{\mathrm{a}}\right) \\
\dot{\varepsilon_{\mathrm{p}}}=\mathrm{C}_{2} \sigma^{\mathrm{n}},
\end{gathered}
$$

and,

where $\sigma$ is the applied stress, $E$ is the Young's Modulus, $\alpha$ is a variable that is equal to the inverse of the relaxation time constant and is representative of the viscoelastic behavior. and $C_{1}$ and $C_{2}$ are constants. Eq. 3 was proposed by Pao and Marin because they argued that the transient or anelastic strain is not proportional to the stress, but to stress raised to some power. In addition, Pao and Marin acknowledged in Eq. 3 that the anelastic strain rate decreases with an increase in the unclastic strain and approaches zero when the anelastic strain reaches an asymptotic value. From Eq. 3, the relation containing $\varepsilon_{a}$ can be rewritten for any function of stress that is dependent on time as:

$$
\dot{\varepsilon}_{\mathrm{a}}+\alpha \varepsilon_{\mathrm{a}}=\alpha C_{1} \sigma^{\mathrm{n}}=\alpha C_{1} F(t)
$$

where $F(t)$ can be used to represent any time dependent function of stress. Eq. 5 is a first order differential equation and the solution can be obtained using laplace transforms. The solution is

$$
\varepsilon_{\mathrm{a}}=\alpha \mathrm{C}_{1} \int_{0}^{\mathrm{t}} \mathrm{F}(\mathrm{t}-\xi) \mathrm{e}^{-\alpha \beta} \mathrm{d} \xi
$$

where $\xi$ is the shift or translation time (a property of the LaPlace transform). The solution to $\mathrm{Eq}_{i} 4$ is simply

$$
\varepsilon_{\mathrm{p}}=\int \dot{\varepsilon_{\mathrm{p}}} \mathrm{dt}=\mathrm{C}_{2} \int_{0} \sigma^{\mathrm{n}} \mathrm{dt}
$$

For static creep $(\sigma=$ constant; the PM model represents the total creep strain as

$$
\varepsilon_{t^{\prime}}=\frac{\sigma}{E}+C_{1} \sigma^{n}\left(1-e^{-\alpha t}\right)+C_{2} \sigma^{n} t
$$

This model may ultimately be used for static, dynamic, and cyclic stressing, as long as the correct time dependence of stress is employed. The PM model predicts that the total strain as a function of time (combining Eqs. 2, 6, and 7) for any static or non-static stręssing condition is:

$$
\varepsilon_{\mathfrak{t}^{\prime}}=\frac{\sigma}{E}+\alpha C_{1} \int_{0} F(t-\xi) e^{-\alpha \xi} d \xi+C_{2} \int_{0}^{t} \sigma^{n} d t .
$$

Eq. 9 simplifies to Eq. 8 when a constant stress is applied. 
The PM model represents the plastic component of creep as being linearly dependent with time (i.e., a viscous-like, permanent creep response that ultimately represents steadystate creep). As shown in Fig. 1, the plastic component of creep is not linear with time for the $\mathrm{Si}_{3} \mathrm{~N}_{4}$ investigated in the present study. The plastic strain is dependent on time to an exponent less than one. Furthermore, the plastic component of creep constitutes a significant contribution to the total creep strain, especially at long times. Fig. 2 shows that the magnitude of the total recovered anelastic strain becomes more insignificant as the total creep strain increases with time. This is an important observation because it reveals that the plastic strain eventually becomes the dominant contributor to the total strain at $1370^{\circ} \mathrm{C}$ in PY6 silicon nitride. A time exponent not equal to one and the eventual dominance of the plastic strain on the total creep strain amplifies the error associated with the assumption that the plastic strain is linearly dependent with time. To address these issues, the PM model was modified in the present study by introducing a time exponent (m) parameter into the plastic strain term (i.e., the third term in Eq.9). The modified Pao and Marin (MPM) model then is represented as:

$$
E_{\mathrm{t}}=\frac{\sigma}{\mathrm{E}}+\alpha C_{1} \int_{0}^{\mathrm{F}} \mathrm{F}(\mathrm{t}-\xi) \mathrm{e}^{-\alpha \xi} \mathrm{d} \xi+\mathrm{C}_{2} \int_{0}^{\mathrm{t}} \sigma^{\mathrm{n}} \mathrm{t}^{\mathrm{m}} \mathrm{dt},(10)
$$

where $\varepsilon_{t}$ now represents the total strain for any time. The modified plastic term in Eq. 10 will be referred to as $\varepsilon_{\mathrm{pm}}$. In addition, a different stress exponent $\left(n^{\prime}\right)$ for the modified anelastic strain $\left(\varepsilon_{a m}\right)$ was also introduced to account for the possibility that the stress exponent for the anelastic strain term may not be the same as that for the plastic strain term. As an example of this for the case of an applied static stress. $\mathrm{n}^{\prime} \neq \mathrm{n}$ in the second term of Eq. 8. Qualitative descriptions of the independent elastic, anelastic, and plastic components for the PM and the MPM models are schematically stown in Fig. 3 .

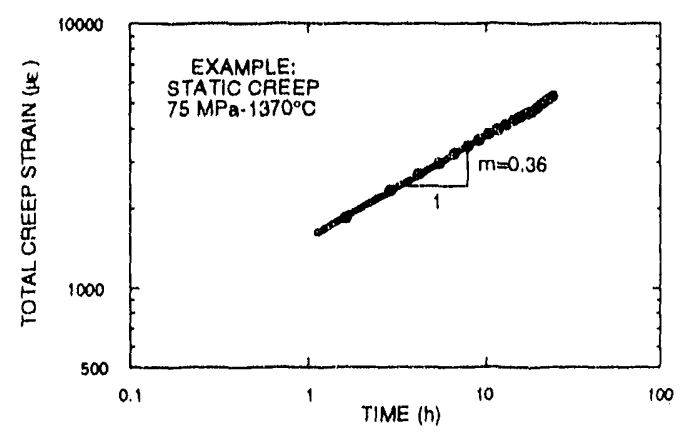

FIG. 1. FOR PY6 SILICON NITAIDE, THE PLASTIC COMPONENT OF CREEP IS DEPENDENT ON TIME TO AN EXPONENT LESS THAN ONE.

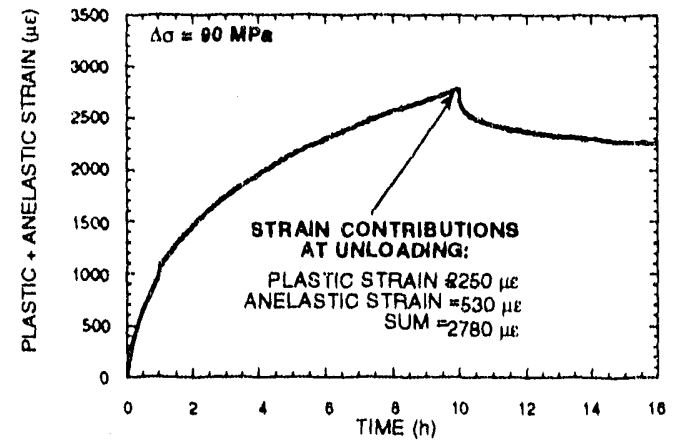

FIG. 2. AS THE TOTAL ACCUMULATED STRAIN $\left(\varepsilon_{1}\right)$ INCREASES, THE RATIO OF $\varepsilon_{a}{ }^{1 / \varepsilon_{1}}$ BECOMES SMALLER, $\varepsilon_{a}^{\prime}$ IS CONSTANT AND DEPENDS ONLY ON THE CHANGE OF STRESS ASSOCIATED WITH UNLOADING.

Pao \& Marin Reprosontation:

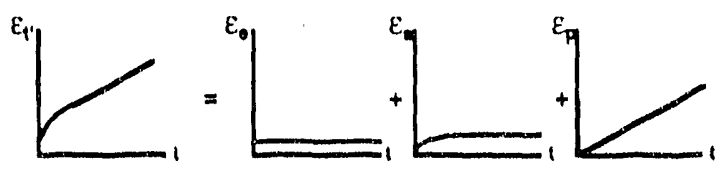

Maditiod Pao \& Marn Ropresentation:

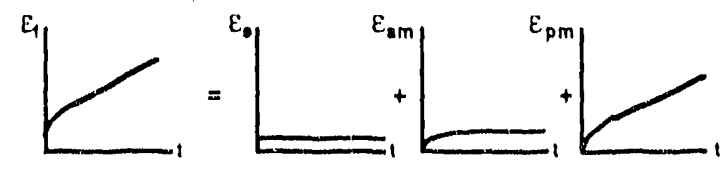

FIG. 3. EXAMPLES OF QUALITATIVE STRAIN RESPONSES FOR AN APPLIED STATIC STRESS ARE SHOWN FOR THE MP AND MPM MODELS.

\section{Experimental Results}

Strain Relaxation Behavier. Strain relaxation tests were conducted at $1370^{\circ} \mathrm{C}$ to determine the values of the parameters which describe the anelastic strain, $\varepsilon_{a m}$. The strain relaxation behavior characterized from unloading was taken as congruent to the behavior on loading. which has heen previously demonstrated for HIPed silicon nitride (Wereszczak. Kirkland, and Ferber, 1994). The strain recovery and the primary creep mechanisıns are believed to be equivalent and result from the viscoelastic response of the amorphous grain boundary phase and the sliding of the grain boundaries, which is accommodated by the elastic deformation of the material adjacent to grain asperities between the grains (Lange, Clarke, and Davis, 1980).

The relaxation time constant $(q), \alpha, n$, and the constant $C_{1}$ were determined. $\alpha$ is simply tho inverse of q (i.e., $(\alpha=1 / 4$ ). 
For this test, a tensile stress of $100 \mathrm{MPa}$ was reduced to approximately $7 \mathrm{MPa}$; it was not completely removed to maintain specimen alignment. Several relaxation tests were conducted to examine any dependence of $q$ on: (1) the hold time $(0.1,1 \mathrm{~h}$, and $10 \mathrm{~h})$ at $100 \mathrm{MPa}$ prior to load removal, (2) different amounts of total creep strain, and (3) the amount of stress removed $(\Delta \sigma)$. It was found that $q$ was independent of the hold time at peak stress prior to unloading and also independent of the total strain accumulated. The total amount of $\varepsilon_{a}$ recove I $\left(\varepsilon_{a^{\prime}}\right)$ was found to be linearly dependent on $\Delta \sigma$ over the ch ges in stress examined (i.e., $n^{\prime}=1$ ). It exhibited the relation $a^{\prime} \approx 6 \cdot \Delta \sigma$ for $54 \mathrm{MPa} \leq \Delta \sigma \leq 93 \mathrm{MPa}$ where $\varepsilon_{\mathrm{a}^{\prime}}$ ard $\sigma \mathrm{h}$; units of $\mu \varepsilon$ and $\mathrm{MPa}$, respectively. An example of a strain claxation test history is shown in Fig. 4 . The elastic load, $\varepsilon_{e}$, is subtracted out from the strain shown in Fig. 4, so the decay shown is strictly due to anelastic recovery, $\varepsilon_{a m}$. The relaxation time constant is equal to the time it took for $63 \%$ (i.e., $e^{-1}$ ) of $\varepsilon_{a^{\prime}}$ to recover. Although it was debatable whether or not $\varepsilon_{a^{\prime}}$ was indeed ever altained, (i.e., $\dot{E}_{\mathbf{a}}=0$ ), even after clays at the unloaded stress, in practicality $\dot{e}_{\mathrm{a}} \approx 0$ after $\approx 4-5$ hours. It was determined that $q=0.7 \mathrm{~h}=2500 \mathrm{~s}$ or that $\alpha=1.4 \mathrm{~h}^{-1}=0.0004 \mathrm{~s}^{-1}$. A single relaxation time constant was determined to represent the relaxation behavior for the sake of simplicity, however, evidence suggests that a spectrum of relaxation constants may be more representative (Lange, Clarke, and Davis, 1980, and Arons and Tien, 1980). Combining the data from Fig. 4 with Eq. 7, $\mathrm{C}_{1}$ was determined to be $2.6 \times 10^{-3} / \mathrm{a}($. This obtained values for $\alpha, n^{\prime}$, and $C_{1}$ were used in Eq. 10 for all analysis.

Cvelic Fatique Behavior. The strain-time histories for the five cyclic fatigue tests are shown in Fig. 5 and compared with previously generated static creep histories (Ferber and Jenkins, 1992). The test matrix, number of cycles, and times to failure are listed in Table 1 . As the frequency is slowed, the general trend is towards more extensive total creep strain. Specimens PY6-1 and PY6-2 were tested at the two fastest frequencies and their strain-time histories fell hetween the range of the static creep histories of specimens tested at 50 and $60 \mathrm{MPa}$. The average tensile stress of the triangular waveform used in this study was $55 \mathrm{MPa}$, so it is not altogether surprising that the strain-time histories of at least some of the tested specimens fell within this range. Specimens PY6-3, PY6-4, and PY6-5 exhibited more total creep than the static creep test at $60 \mathrm{MPa}$, even though their average stresses were still $55 \mathrm{MPa}$. Possible reasons for the greater total creep strains shown by specimens PY6-3, PY6-4, and PY6-5 will be revisited in later discussion. The strain was not continuously monitored with the contact extensometers for tests PY6-1 and PY6-2 to avoid damage to the instrument, so strain was periodically measured at discrete limes; these are the "tick" marks present in the strain histories of these two tests.

To determine the values of the parameters associated with the plastic component of the MPM model, $E_{p m}$, multi-linear regression (MLR) was employed on static creep data previously generated on PY6, (Ferber and Jenkins, 1992).

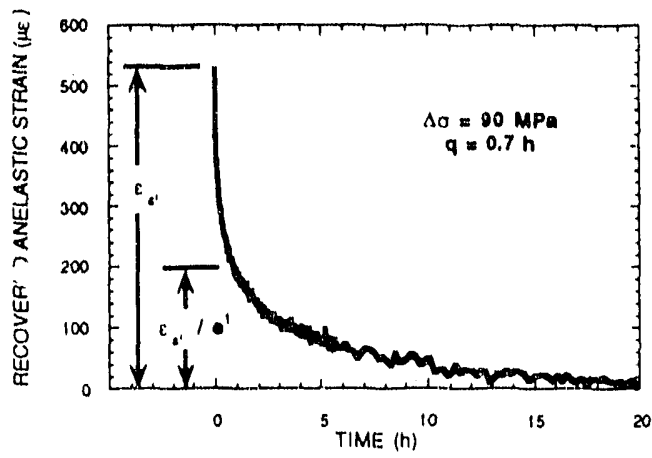

FIG. 4. AN EXAMPLE OF A STRAIN RELAXATION TEST HISTORY' $\varepsilon_{a}^{\prime}$ IS THE TOTAL RECOVERED ANELASTIC STRAIN AND THE RELAXATION TIME CONSTANT, $q$, IS THE TIME IT TOOK FOR $63 \%$ OF $\varepsilon_{\mathrm{a}}{ }^{\prime}$ TO BE: RECOVERED.

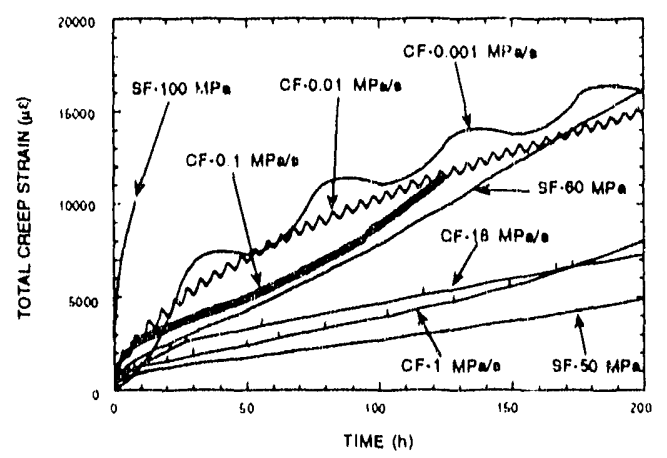

FIG. 5. STRAIN-TIME HISTORIES OF CYCLIC FATIGUE TESTS (CF) ARE COMPARED WITH STATIC FATIGUE (SF) STRAIN HISTORIES GENERATED IN A PREVIOUS STUDY (Ferber and Jenkins, 1992).

MLR on creep strain as a function of stress and lime was performed on the natural logarithm of the integrand in the third term in Eq. 10 or.

$$
\ln \left(\varepsilon_{\mathrm{pm}}\right)=\ln \left(\mathrm{C}_{2}\right)+n \ln (\sigma)+m \ln (t)
$$

for four static creep stresses of $50,68,75$, and $100 \mathrm{MPa}$. It was determined that $C_{2}=0.000104, n=3.256$, and $m=0.324$. It is noteworthy that the stress dependence on the total creep strain was found to be 3.256 in the present study, while the stress dependence on the minimum creep rate was previously determined to be 4.7 for PY6 at $1370^{\circ} \mathrm{C}$ (Ferber and Jenkins, 1992). The time exponent of 0.324 is quite close to the $1 / 3$ predicted by the classical Andrade analysis (Andrade, 1914). The experimental data and the fitted curves are shown in Fig. 6. Even though the total strain is plotted as the ordinate 
Table I. TEST MATRIX AND CYCLIC FATIGUE RESULTS. TRIANGULAR WAVEFORM DESCRIBED BY $R=0.1$ AND $\sigma_{\max }=100 \mathrm{MPa}$.

\begin{tabular}{|c|c|c|c|c|}
\hline $\begin{array}{l}\text { Specimen } \\
\text { ID }\end{array}$ & $\begin{array}{l}\text { Freq. } \\
(\mathrm{Hz})\end{array}$ & $\begin{array}{c}\text { Stress } \\
\text { Rate } \\
(\mathrm{MPa} / \mathrm{s})\end{array}$ & $\begin{array}{l}\text { \# of } \\
\text { Cycles to } \\
\text { Failure }\end{array}$ & $\begin{array}{l}\text { Time to } \\
\text { Fuilure } \\
\text { (h) }\end{array}$ \\
\hline PY6-1 & 0.1 & 18 & $4066000^{*}$ & $1129^{*}$ \\
\hline PY6-2 & 0.0056 & 1 & 4939 & 247 \\
\hline PY6-3 & 0.00056 & 0.1 & 248 & 124 \\
\hline PY6-4 & 0.000056 & 0.01 & 149.5 & 747.5 \\
\hline PY6-5 & 0.0000056 & 0.001 & 8.4 & 419 \\
\hline
\end{tabular}

* Test interrupted, specimen did not fail.

in Fig. 6, the use of it (versus just the plastic strain) does not affect the slope determination of the plastic creep lime exponent (i.e., $m$ ) on the $\log -\log$ plot because the elastic and anclastic contributions are small and effectively constant over the life of the test. These three values of $\mathrm{C}_{2}, \mathrm{n}$, and $\mathrm{m}$ were used in Eq. 10 for all analysis.

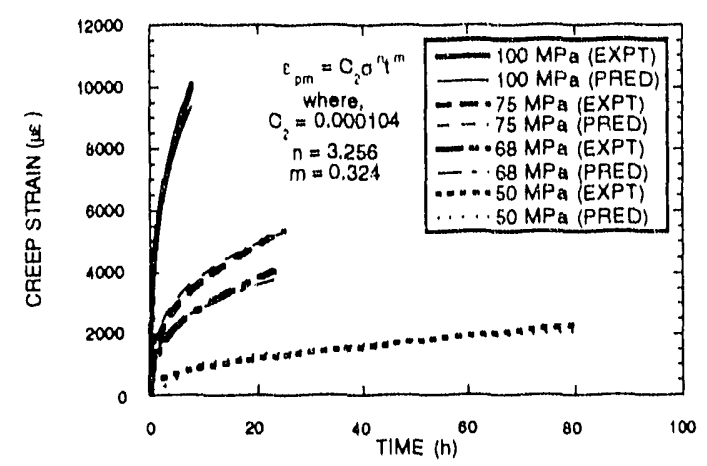

FIG. 6. THE VARIABLES $c_{2}, n$, AND $m$ WERE DETERMINED FROM MULTI-LINEAR REGRESSION OF TOTAL CREEP STRAIN VERSUS TIME FROM STATIC CREEP HISTORIES PREVIOUSLY GENERATED (Ferber and Jenkins, 1992).

The MPM model described by Eq. 10 was used 10 numerically fit the experimental data. The values of the parameters used in the analysis were: $\alpha=1 / q=0.0004 \mathrm{~s}^{-1}$. $C_{1}=0.0026 / \alpha, \quad n^{\prime}=1, \quad E=300 \mathrm{GPa} \quad\left(43.5 \times 10^{6} \mathrm{psi}\right)$, $\mathrm{C}_{2}=0.000104, \mathrm{n}=3.256$, and $\mathrm{m}=0.324$. As an illustrative example, Figs. 7a-b shows an arbitrary triangular waveform and the prediction of elastic, anelastic, and plastic strain, and their sum, for one cycle of an arhitrary triangular waveform. Units of $\mathrm{MPa}$ and $\mu \mathrm{E}$ (or $\mu \mathrm{m} / \mathrm{m}$ ) were used consistently throughout the analysis.
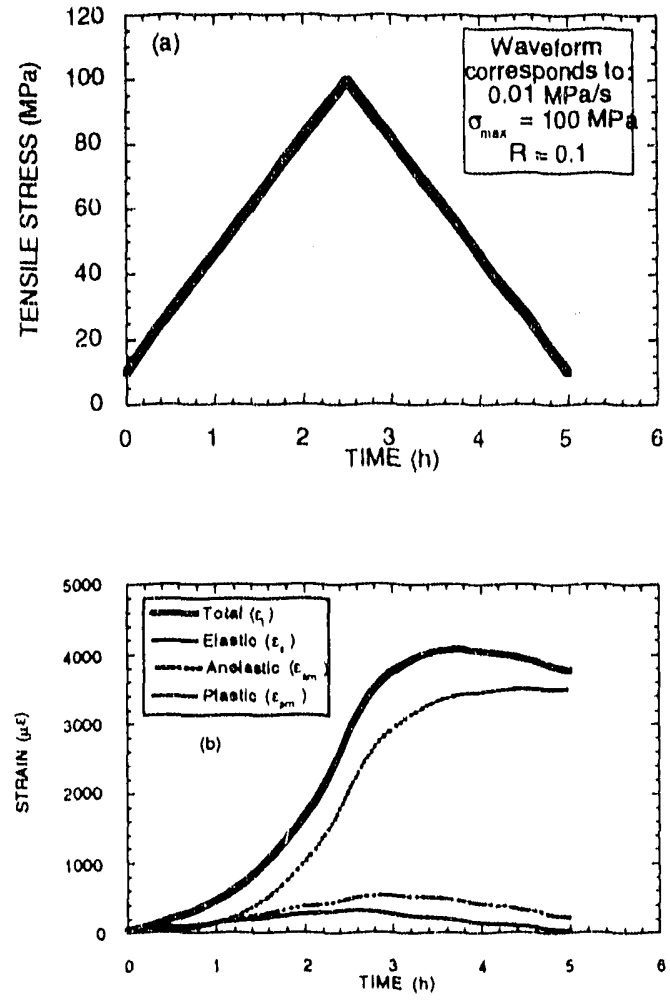

FIG. 7 FOR AN ARBITRARY TRIANGULAR WAVEFORM (a), AN EXAMPLE OF ELASTIC, ANELASTIC, PLASTIC, AND TOTAL STRAINS ARE PREDICTED (b) FOR ONE CYCLE USING Eq. 10.

The predicted fits for the five specimens tested in this study are shown in Fig. 8 along with the experimental creep straintime curves. The experimental cyclic creep curves exhibit continued increases in their total strain indicative of creep rachetting hehavior (Kraus, 1980). A large discrepancy between experimental and predicted cyclic response was observed at faster frequencies or faster stressing rates. This discrepancy lessens as the test frequency was decreased, but it remained substantial for stressing rates equal to and above 0.1 $\mathrm{MPa} / \mathrm{s}$, as shown in Figs. 8a-c. Data was only predicted for durations of about 5.5 and 50 hours for specimens PY6-1 and PY6-2, respectively, because computation time was excessive and the discrepancy between experiment and prediction became evident after short times. The magnitudes of total creep strain predicted for $0.01 \mathrm{MPa} / \mathrm{s}$ were approximately equal to those of the experiment, as shown in Fig. $8 d$, although the creep rates were dissinilar throughout the test duration. The prediction of the cyclic creep response was quite good for the $0.001 \mathrm{MPa} / \mathrm{s}$ test, as shown in Fig. $8 \mathrm{e}$. The predicted total creep strain profile was coincident with the experimental data up to approximateiy 175 hours, but the overall increase in the 
experimental creep rato after $175 \mathrm{~h}$ suggested an onset of tertiary creep. Tertiary creep behavior is a phenomenon that is not addressed in the MPM model.

A possible reason why the MPM model over-predicts the cyclic creep strain at faster test frequencies and stressing rates may be due to the changing nature of the material's elastic stress limit. The effective elastic limit $^{3}$ is a function of the stressing rate for PY6 silicon nitride and decreases with decreasing stressing rate at $1370^{\circ} \mathrm{C}$. This trend has also been reported for hot-pressed silicon nitride (Ohji, et, al., 1987). The dynamic fatigue, stress-strain history was reported by Lin, et. al. (Lin, Jenkin, and Ferber, 1993) for PY6 at $1370^{\circ} \mathrm{C}$. That data traversed over thousands of microstrain, however, only the first $800 \mu \mathrm{E}$ ( or $0.08 \%$ strain) of it are shown in Fig. 9. Four of the five stressing rates shown match rates used in the present cyclic fatigue study: $37 \mathrm{MPa} / \mathrm{s}$ was included as a comparison to show a faster stressing rate response. Although it is somewhat of a subjective determination, the effective elastic limit is somewhere between $\approx 80.100 \mathrm{MPa}$ for $1 \mathrm{MPa} / \mathrm{s}$ and as low as $\approx 30 \mathrm{MPa}$ for $0.001 \mathrm{MPa} / \mathrm{s}$. Note that these stressing rates were used in the present cyclic fatigue tests on specimens PY6-2 and PY6-5, respectively. The MPM
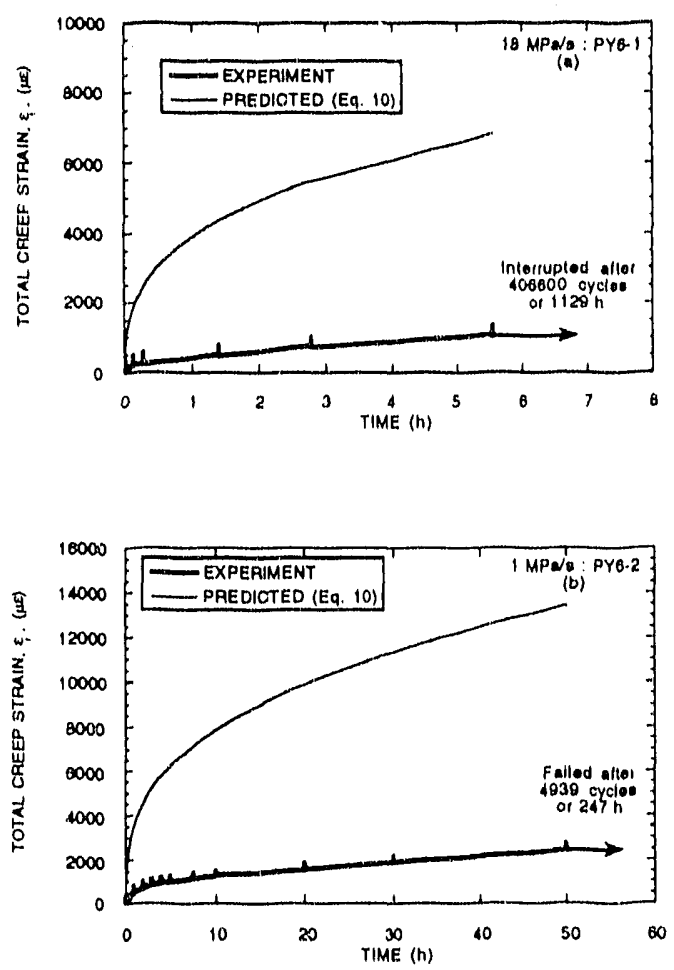

3 The present reference to an "elastic limit" is somewhat of a misnomer. At elevated temperatures where anelasticity is active, the strain limit describing the onset of non-linearity is due to elastic plus anelastic effects (Lubahn, 1953). However, for the sake of convenience, this limit in the present study is referred to as the "elastic limit."
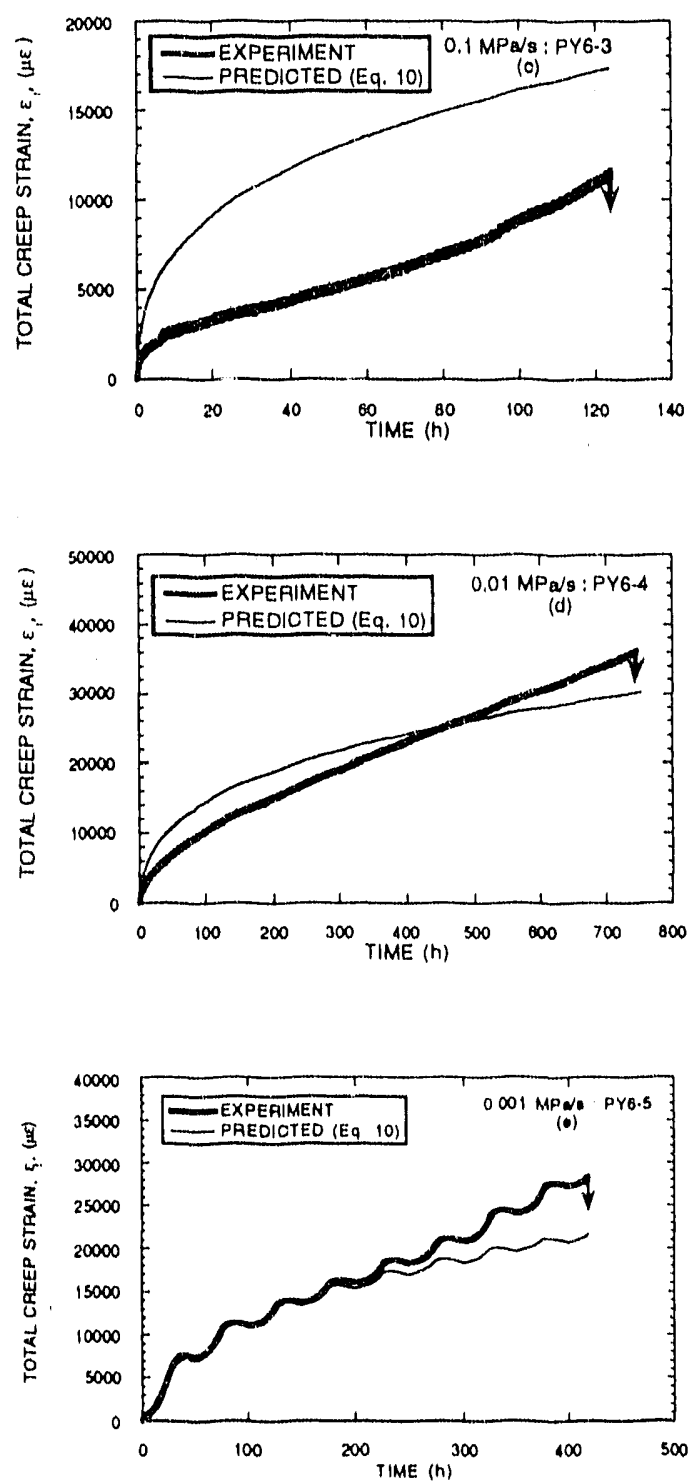

FIG. 8. EXPERIMENTAL CYCLIC CREEP STRAIN AS A FUNCTION OF TIME IS COMPARED WITH DATA PREDICTED USING THE MPM MODEL FOR SPECIMENS (a) PY6-1, (b) PY6-2, (c) PY6-3, (d) PY6-4, and (e) PY6-5.

model predicts a plastic contribution to the total strain for all stresses during each cycle: whereas in the experimental case. there may only be a plastic strain contribution for stresses above the elastic limit for that corresponding stressing rate. For cyclic tests PY6-1, PY6-2, and PY6-3, the frequencies or stressing rates were fast enough where there was not an appreciable amount of time above the elastic limit for each stressing rate to accumulate the total strain predicted by the 
MPM model. This lack of acknowledgment of the elastic limit will cause the MPM model to consistently over predict the total cyclic creep strain at faster frequencies or stressing rates, At the slower stressing rates of 0.01 and $0.001 \mathrm{MPa} / \mathrm{s}$, the relatively low elastic limit coupled with the long times that the stress in each cycle is in excess of it results in more representative predictions of total cyclic creep strain.

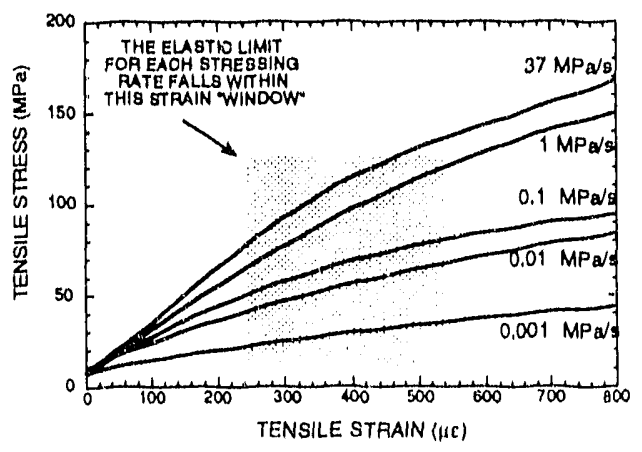

FIG. 9, AS THE STRESSING RATE IS DECREASED, THE ELASTIC LIMIT DECREASES AND PLASTIC CREEP OCCURS AT LOWER STRESSES. CREEP STRAIN DATA IS EXTRACTED FROM REPORTED TESTS IN Lim, ot. al., 1993.

Instead of a critical or elastic stress limit argument, the perspective of a threshold strain to explain the cyclic creep behavior also may be used. In this case, plastic strain only accumulates if $\varepsilon_{a m}$ is saturated or reaches some threshold anelastic strain (l.e., $\varepsilon_{\mathrm{pm}}$ increases only if $\varepsilon_{a m}=\varepsilon_{a^{\prime}}$ or $\left.\varepsilon_{\mathrm{am}}=\mathrm{constant} \cdot \varepsilon_{\mathrm{a}^{\prime}}\right)$. The basis for this comes from at least two sources. Lin, et.al, 1994, experimentally found that cyclic loading of PY6 $(0.1$ and $10 \mathrm{~Hz})$ at $1370^{\circ} \mathrm{C}$ always yrelded less accumulated creep strain and longer lifotimes than static loading at comparable stresses. In that study, it was speculated that the viscoelastic or anelastic nature of the secondary phase acted in concert with the fast cyclic loading and unloading to slow the normal accumulation of creep damage. In a second study, cavitation (a permanent or plastic damage mechanisin) was shown to account for as much $85 \%$ of the total creep strain (Luecke, et al, 1993); however, the attainment of a small amount of accumulated strain was necessary before cavities were detected. Both these studies support the claim that a critical strain (in this case, an anelastic strain) needs to be attained in order for plastic deformation to become active. This critical strain may indeed be stress dependent in a similar fashion to the dependence of $\varepsilon_{a^{\prime}}$ un the $\Delta \sigma$ from the strain relaxation studies. If the anelastic strain is saturated, then no more anelastic strain can be accommodated and high local stress intensities may develop which act to nucleate cavities. The MPM model does not take into account that the onset of plastic deformation requires a threshold of anelastic strain to be met; consequently, it will over predict the plastic stratn at faster frequencies or stressing rates where the critical strain is not attained. Indeed there is some accumulation of plastic strain evident in Figs. 8 a-c for the faster frequencies; therefore, for this argument to be valld, an anelastic strain threshold inust have been met for each cycle although the corresponding accumulation of plastic creep was relatively small. Of the arguments based on the plastic strain first requiring the attainment of a critical stress or strain, the latter is more versatile because it can more easily reconcile plastic deformation under fast frequency cyclic and static loading conditions.

In the future, the MPM model will be further refined to predict creep strain whose plastic component only becomes activated once an elastic stress limit is exceeded or an anelastic strain threshold is saturated. This refinement shall correct, or at least lessen, over predicted creep strains and more accurately reflect cyclic creep response of materials such as PY6 silicon nitride.

\section{CONCLUSIONS}

The amount of tension-tension cyclic creep strain was found to increase as the frequency or stressing rate of a triangular waveform $\left(\sigma_{\max }=100 \mathrm{MPa}\right.$ and $R=0.1$, average stress of cycle $=55 \mathrm{MPa})$ decreased for PYG silicon nitride at $1370^{\circ} \mathrm{C}$. For frequencies of 0.1 and $5.6 \times 10^{-3} \mathrm{~Hz}$ (stressing rates of 18 and $1 \mathrm{MPa} / \mathrm{s}$, respectively), the amount of cyclic creep strain fell within a range bounded by static creep responses of 50 and $60 \mathrm{MPa}$. The total cyclic creep strain increased continually for comparable times for frequencies of $5.6 \times 10^{-4} \mathrm{~Hz}, \quad 5.6 \times 10^{-5} \mathrm{~Hz}$ and $5.6 \times 10^{-6} \mathrm{~Hz}$ (stressing rates of $0.1,0.01$, and $0.001 \mathrm{MPa} / \mathrm{s}$, respectively).

A modified Pao and Marin model was successful at predicting representative low-frequency, cyclic creep responses from data and creep parameters extended from static creep and strain relaxation tests. The model predicted cyclic creep strains similar to those experimentally determined for $5.6 \times 10^{-5} \mathrm{~Hz}$. It very accurately predicted the cyclic creep response for $5.6 \times 10^{-6} \mathrm{~Hz}$.

The modified Pao and Marin did not satisfactorily predict cyclic creep response at frequencies equal to and faster than $5.6 \times 10^{-4} \mathrm{~Hz}$. The model overpredicted the cyclic creep strains at these faster frequencies. The model predicts the contribution of plastic strain for all stresses in the cyclic waveform used, however, it is evident that an elastic stress limit or an anelastic strain threshold needs to be attained prior to the accumulation of plastic strain.

\section{ACKNOWLEDGMENTS}

Research sponsored by the U.S. Department of Energy, Assistant Secretary for Energy Efficiency and Renewable Energy, Office of Transportation Technologies, as part of the Ceramic Technology Project of the Propulsion System Materials Program, under contract DE-AC05-84OR21400 with Martin Marietta Energy Systems, Inc.

The authors wish to thank Dr.'s B. Gieseke, H, -T, Lin, and A. E. Pasto for reviowing the manuscript and for their helpful suggestions and comments, C. -K. J. Lin was a post-doctoral 
researcher at the High Temperature Materials Laboratory at the time of this study.

\section{REFERENCES}

Andrade, E. N. da C., 1914, "The Viscous Flow in Metals und Allied Phenomena," Proc. Roy, Soc, Vol, A90, p 329.

Arons, R. M. and Tien, J. K., 1980, "Creep and Strain Recovery in Hot-Pressed Sillicon Nitride," J. Mat. St:S., Vol. 15, pp 2046.58.

Ding, J. -L., Liu, K. C., More, K. L., and Brinkman, C., R., 1994. "Creep and Creep Rupture of an Advanced Silicon Nitride Ceramic," J. Am. Cer. Soc., Vol. 77. No, 4, pp 867-74.

Ferber, M. K., and Jenkins, M. G., 1992, "Evaluation of the Strength and Creep.Fatigue Behavior of Hot Isostatically Pressed Silicon Nitride," J. Am. Cer. Soc., Vol. 75, No. 9, pp 2453-62.

Kraus, H., Creep Analysis, 1980, John Wiley \& Sons, New York.

Lange, F, F., Clarke, D. R., and Davis, B. I., 1980, "Compressive Creep of $\mathrm{Si}_{3} \mathrm{~N}_{4} / \mathrm{MgO}$ Alloys, Part 2, Source of Viscoelistic Effect," J. Mat. Sci., Vol. 15, pp 611-15.

L.in, C. .K. J., Jenkins, M. G., and Ferber, A1. K., 1993, "Tensile Dynamic and Static Fatigue Relations for a HIPed Silicon Nitride at Elevated Temperatures," J. Eur. Ćer.Soc,. Vol. 12, pp 3-13.

Lin, C. -K. J., Jenkins, M. G., and Ferber, M. K., 1994, "Cyclic Fatigue of Hot-Isostatically Pressed Silicon Nitride at Elevated Temperatures," J. Mat. S'ci., Vol. 29, pp 3517-3526.

Liu, K. C., and Brinkunan, C. R., 1987, "Dynamic T'ensile Cyclic Fatigue of $\mathrm{Si}_{3} \mathrm{~N}_{4}$," Proc, of the 25th Automotive Technology Development Contractors' Coordination Meeting. P-209, pp $189-197$.

Lubahn, J. D., 1953, "The Role of Anelasticity in Creep, Tension, and Relaxation Behavior," Trans. of the A.S. M., Vol, 45, pp 787-838.

Luecke, W., Wlederhorn, S. M., Hockey, B. J., and Long, G. G., 1993, Silisen Nitride Ceramics, V287, Mat. Res. Soc. Symp. Proc., Eds. I, -W. Chen et. al., pp 467-72.

Menon, M. N., Fang, H. T., Wu, D. C., Jenkins, $M$. $Q$., Ferber, M. K., More, K. L., Hubbard, C. R., and Nolan, T. A. 1994, "Creep and Stress Rupture Behavior of an Advanced Silicon Nitride: Part 1, Experimental Observations," J. Am. Cer. Soc., Vol. 77, No. 5, pp 1217-27.

Ohji, T., Sakai, S., Ito, M., Yamauchi, Y., Kanematsu, W., and Ito, S., 1987, "Yielding Phenomena of Hot-Pressed $\mathrm{Si}_{3} \mathrm{~N}_{4}$," High Temperature Techology, Vol. 5, pp 139-44.

Pao, Y. -H., and Marin, J., 1953, "An Analytical Theory of the Creep Deformation of Materials," J. Appl. Mech., No. 6, pp 245-252.

Wereszczak, A. A. Kirkland, T. P., and Ferber, M. K., 1994, "Stress and Strain Relaxation Behaviour in HIPed Silicon Nitrides," J. Mat. Sci. Lett., Vol. 13, pp 1469-71.

\section{NOMENCLATURE}

$\alpha$ Inverse of the relaxation time constant

$C_{1}$ Constant that is present in the anelastic strain representation

$\mathrm{C}_{2}$ Constant that is present in the plastic strain representation

$\varepsilon_{a} \quad$ Anclastic strain

$\dot{E}_{11} \quad$ Anclastic strain rate

$E_{\mathrm{a}}{ }^{\prime} \quad$ Maximum anclastic strain for a corresponding change in stress

Eun Anclastic strain of the modiffed Pao and Marin model

$\varepsilon_{\mathrm{e}} \quad$ Elastic strain

$\varepsilon_{\mathrm{p}} \quad$ Plastic strain

$\varepsilon_{\mathrm{p}} \quad$ Plastic strain rate

$E_{p(n)} \quad$ Plastic strain of the modified Pao and Marin model

$\varepsilon_{1}$ Total creep strain of the modified Pao and Marin model

$E_{1}^{\prime} \quad$ Total creep strain of the Pao and Marin model

E Young's Modulus

MLR Multi-linear regression

MPM Modified Pao and Marin model

n Stress exponent - plastic strain

$n^{\prime} \quad$ Stress exponent - anclastic strain

PM Pao and Marin model

q Relaxation time constant

$\mathrm{R}$ Minimum to maximum stress ratio

$\sigma \quad$ Stress

$\sigma_{\text {IIax }}$ Maximum stress

$\sigma_{\text {nun }}$ Minimum stress

$\Delta \sigma \quad$ Caunge in stress

1 Time

$\xi \quad$ Laplace transform shift or translation time 

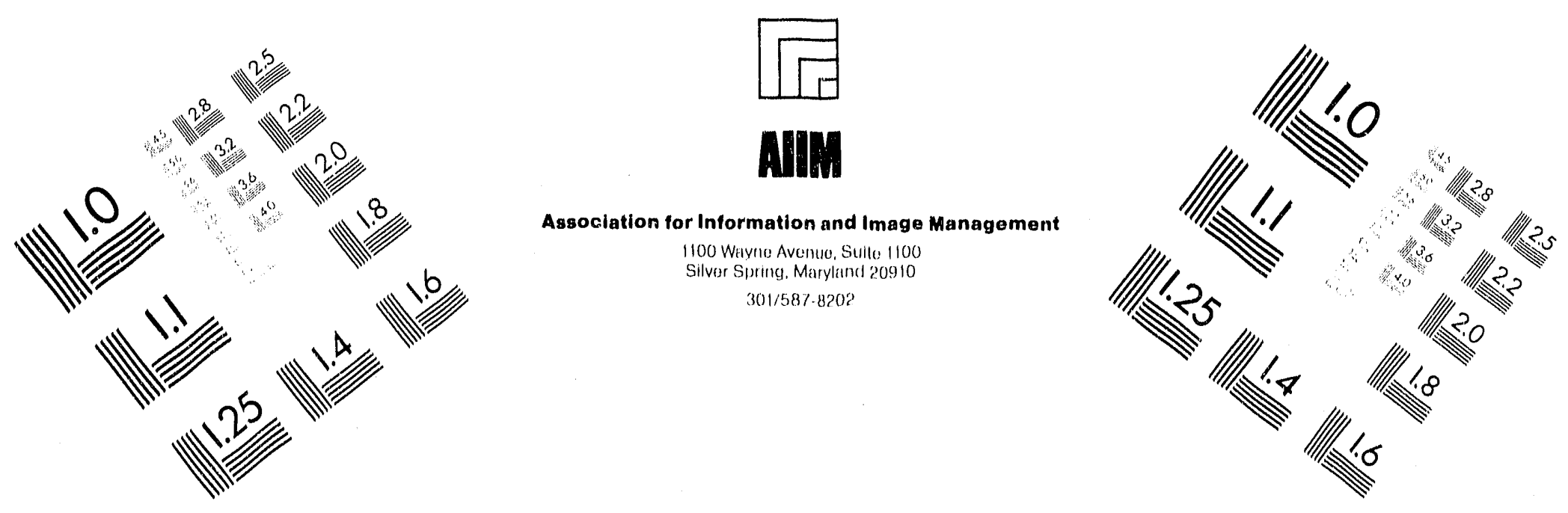

\section{Centimeter}

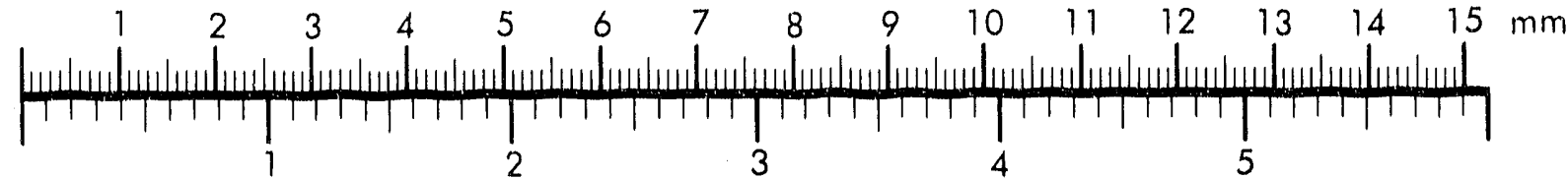

Inches
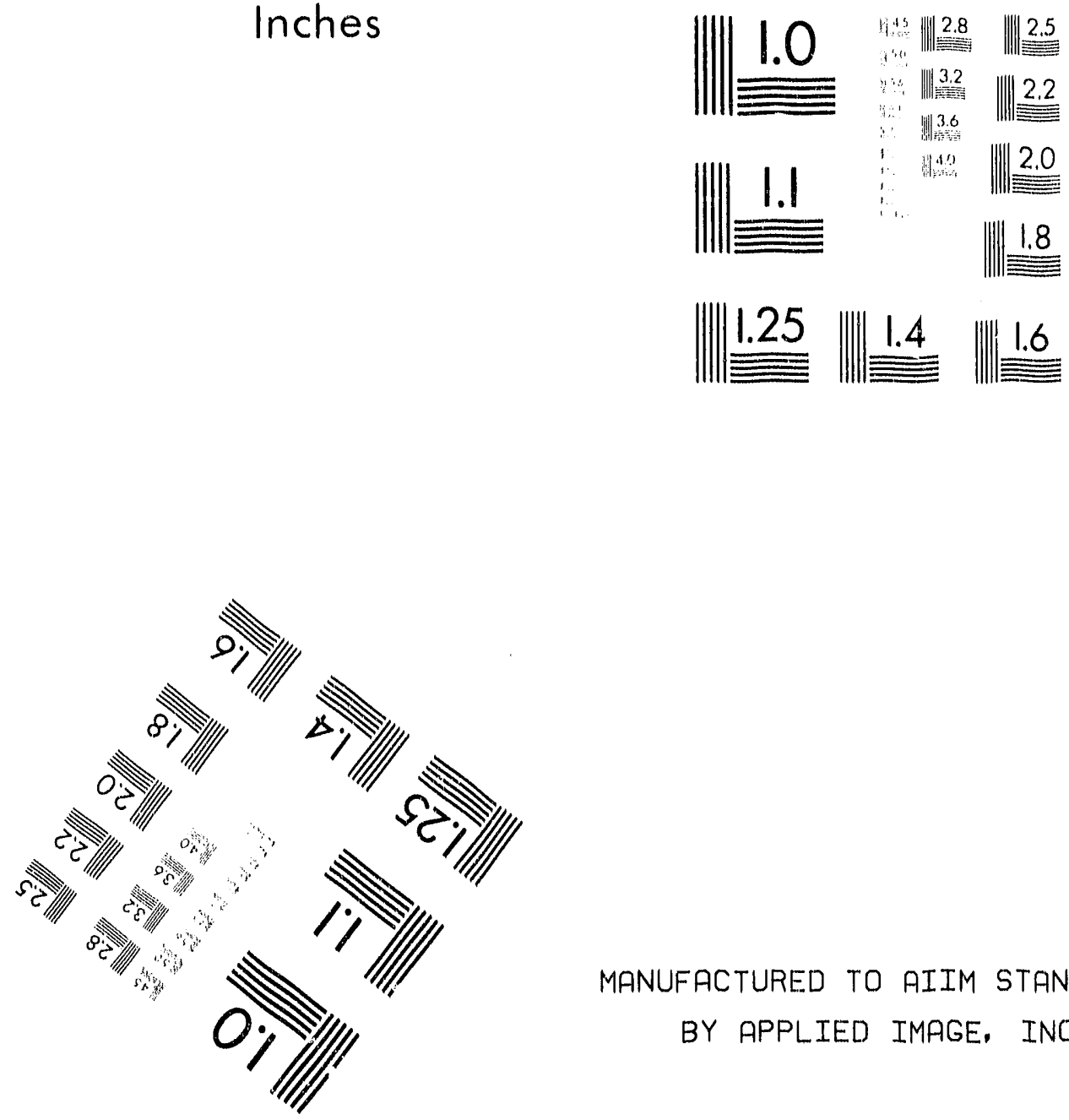

MANUFACTURED TO AIIM STANDARDS

BY APPLIED IMAGE, INC.

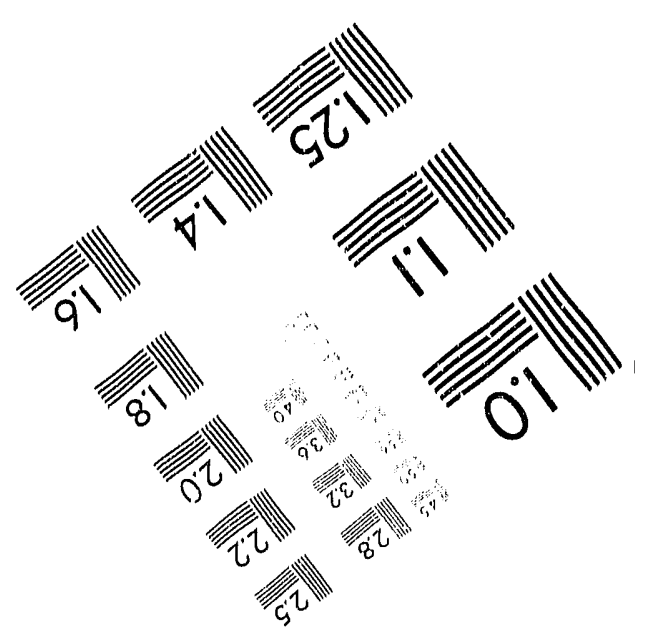




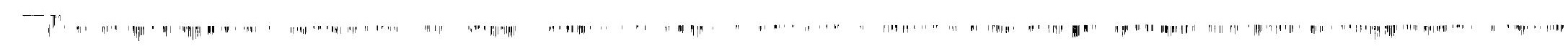



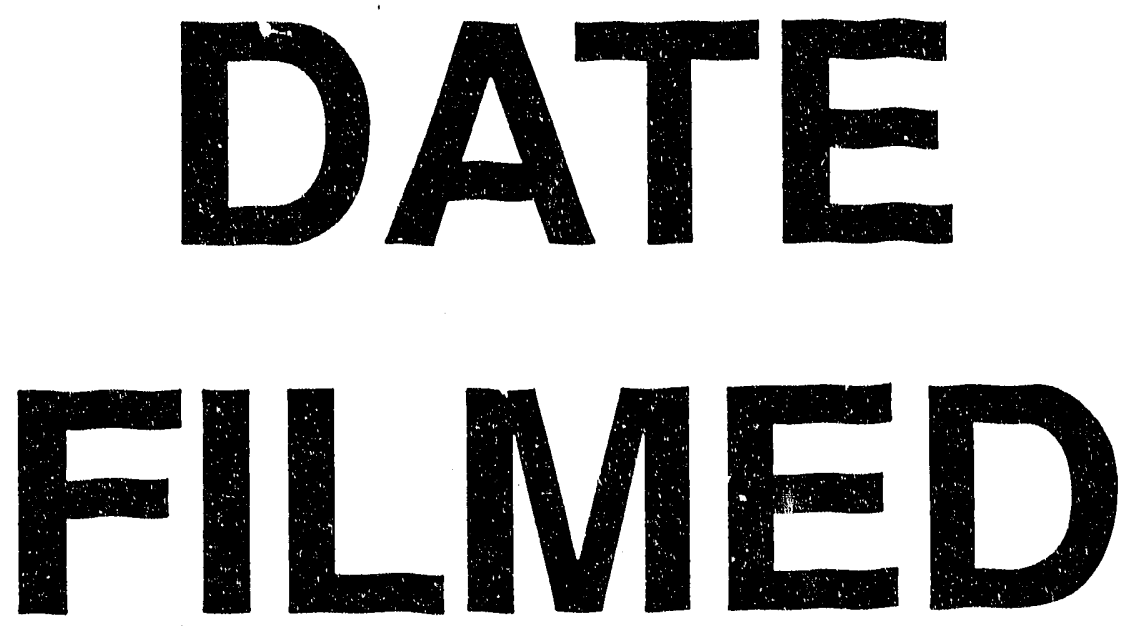

$6 / 21 / 95$
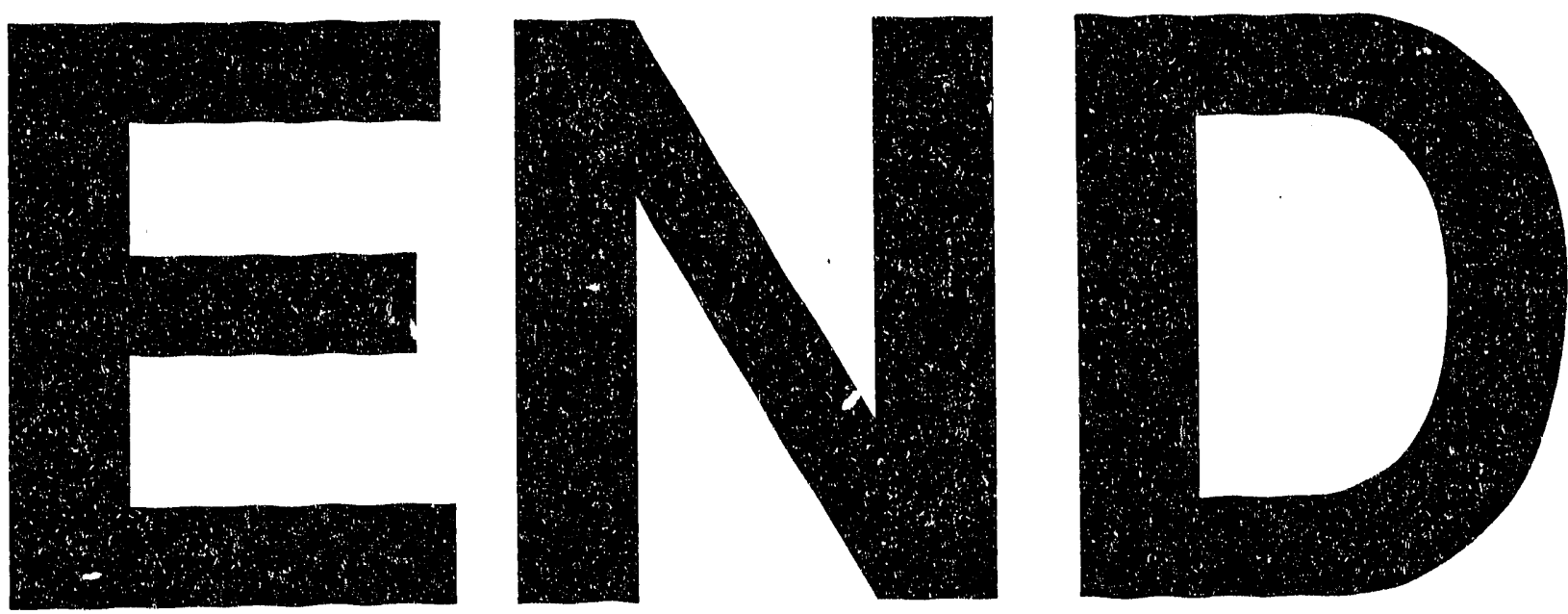